\title{
ANALYSIS OF THE MARRIAGES AND DIVORCES SEASONALITY IN ROMANIA COMPARED TO BACAU COUNTY DURING 2010-2013
}

\author{
Eugenia Harja \\ “Vasile Alecsandri” University of Bacau \\ eugenia.harja@ub.ro
}

\begin{abstract}
It is known that the number of marriages concluded in general in a geographic area follows a cyclical trend due primarily to religious factors. In this study we wanted to test whether this assumption is maintained in the past four years. On the other hand, we wanted to look at the indices of seasonality in Romania compared to those calculated for Bacau County to see if there are significant differences. The same aspects were analyzed for the divorce evolutions, to identify whether there is a seasonal trend in this case as well. After applying the methods of arithmetic mean and the mobile averages, there were calculated the seasonality indices and concluded that marriages are clearly cyclical developments every 12 months, with a peak in the third quarter, respectively in August, when the number is 3,5 times higher than the monthly average yearly in Bacau County and 2,3 times for Romania. In the case of divorces, the evolution is oscillatory, but without identifying a seasonal component. The average monthly number of divorces per 100 marriages is 29 in Romania and 36 in Bacau, with a maximum of 202 in the county of Bacau, observed in March 2010.
\end{abstract}

Keywords

marriage; divorce; mobile average; seasonality indices

JEL Classification

C10; J10; J11

Role of family policies and the influence of the religious phenomenon over demographic developments

Demographic changes in Romania since the '90s led to changes in the age groups, emphasizing the growing imbalance in recent years. Decrease in the proportion of young people and the increase of elderly in the total population has many repercussions on the labor market and social effects that can hardly be stopped. For a balanced development of population by age groups, policy measures to stimulate the birth rate are necessary, and this is linked on the other hand to the cultural aspects of the population, being greatly influenced by traditions and especially the religious factor. Even if the behavior of many young people has changed in recent years towards family and marriage, culture and religious traditions in our country are still a strong influence for birth. In recent years, more and more young people prefer to live in a consensual union, delaying the time to formalize their relationship through marriage. With all these changes in behavior, most prefer to raise their children in the legal framework of marriage, respecting the church canons and traditions. For this reason marriage has influence on birth, and the family policies are designed to encourage childbirth. A young and renewed population and provide ensures a dynamic and a balance both economically and socially to a state, while an aging population causes major imbalances in this regard. 
Family policies are designed to encourage families and to make sure that families with children have an average income per person close to the families without children. A special role in this regard is owned by the church, which does not accept legally unmarried couples, this still being a powerful influence in the determination of young people to formalize their relationship and give birth to children within marriage. A child born out of marriage is often rejected by society, which is why most couples keep the traditional model of marriage.

The influence of the religious factor can be well observed in the history of the moment of conclusion of most marriages, which take into account the periods of fasting and legal holidays, when the Church prohibits formalizing religious marriages. Or, as most youngsters prefer to formalize legally the marriage on the same day, or at least after a few days after the religious formalization, it can be observed that every year, the peak months of the number of marriages formalized are exactly those after the periods of fasting. These issues will be statistically demonstrated in the third part through the application of calculation methods of the seasonal fluctuations.

\section{Evolution in the number of marriages and divorces during 2010-2014}

After the 90's, the number of marriages has been in continuous decline in Romania, mainly due to the decrease in population and behavioral modification of the couples. Thus, in Romania the number of marriages decreased by 44,2\% in 2013 compared to 1990 and in Bacau County it has almost halved. Meanwhile, the number of divorces in the country has been constant, around 30.000 annually, while in Bacau County it has grown over time, the years 1998 and 1999 almost doubling compared to 1990 .

I was saying that in time people's behavior towards marriage has changed, this can be noticed after the age of spouses at marriage. Most young people desire to make a career first, and on the other hand the increase of the professional activity of women, made that the formalizing of first marriages to be postponed. Thus, in Romania the average age for the first marriage increased in conclusion for husband from 25 years in 1990 to 29,6 years in 2012 (+4,6 years), and for the wife from 22 years to 26,4 years $(+4,4$ years). The average age for the first marriage is lower in Bacau county, for the husband it increased from 24,7 years in 1990 to 29,3 years in $2012(+4,54$ years), and for the wife from 21,7 years to 25,6 years in 2012 (+3,9 years). The situation is different in the two areas of social life, the average age is higher in urban than in rural areas with at least a year for spouses and at least two years for wives, both in Bacau county and the national average. At the end of the period, the average age for the first marriage for husband nationally was 30 years in urban areas (Bacau, 29,7) and 28,9 in rural areas (Bacau, 28,7) and for the wife, of 27,3 years in urban areas (Bacau, 26,7) and 24,8 years in the rural area (Bacau, 24,).

Accordingly, it increased over time as well the average age of marriage in general, from 26,9 years, the national average for husband, to 31,6 years at the end of the period, and for the wife from 23,7 years to 28,2 years. Environment and sex differences are preserved in this case.

For both husband and wife, the structure of the marriages after the first legal one has changed. In both cases, at the date of marriage, if in the 90s around $88-89 \%$ of spouses had never been married before, about $2 \%$ were widowed and $8-9 \%$ were divorced, at the end of the period there were married around $85 \%$ of the spouses, slightly above $1 \%$ were widowed, and between $13-14 \%$ were divorced.

In parallel with the formalizing of marriages, other legal unfold. If the number of divorces in the country has remained somewhat constant annually, the number in Bacau county has increased. Bacau County divorce rate increased from 1,32\% in 1990 to almost 2\% during 2010-2011 and 1,58\% in 2012. Currently, the rate is nearly two times higher in urban than in rural areas $(2,16 \%$ in urban and $1,11 \%$ in rural 
areas), compared to the 90 s when it was $2,15 \%$ in urban areas and only $0,58 \%$ in rural areas, the difference being in significant decrease in the last 24 years.

Divorce rate in Bacau county had a parabolic trend in the last 24 years, both overall and on the two areas, with a maximum during 1998-2000.

In terms of age structure of the spouses at the time of divorce, it changes slightly in favor of older ages, this because it increased the age of marriage. If in the $90 \mathrm{~s} 23,2 \%$ of divorced wives were below 24 years, in 2012 only 9,3\% of them are found in this age group. Group of 40-44 years, the proportion of divorced women was about $9 \%$ in the early years, as today to rise to $16 \%$. In all age groups after 40 years the share of divorces has increased.

Table 1 Average monthly number of marriages and divorces in Romania and Bacau county during 2010-2013

\begin{tabular}{|l|r|r|r|r|r|r|}
\hline \multirow{2}{*}{ Month } & \multicolumn{2}{|c|}{$\begin{array}{c}\text { Marriages } \\
\text { Monthly average }\end{array}$} & \multicolumn{2}{c|}{$\begin{array}{c}\text { Divorces } \\
\text { Monthly average }\end{array}$} & \multicolumn{2}{c|}{$\begin{array}{c}\text { Number of } \\
\text { divorces at an } \\
\text { average of } 100 \\
\text { marriages }\end{array}$} \\
\cline { 2 - 8 } & Romania & $\begin{array}{c}\text { Bacau } \\
\text { county }\end{array}$ & Romania & $\begin{array}{c}\text { Bacau } \\
\text { county }\end{array}$ & Romania & $\begin{array}{c}\text { Bacau } \\
\text { county }\end{array}$ \\
\hline January & 3998 & 147 & 2149 & 132 & 54 & 90 \\
\hline February & 4239 & 126 & 2965 & 100 & 70 & 80 \\
\hline March & 3753 & 95 & 3345 & 125 & 89 & 132 \\
\hline April & 5748 & 139 & 2901 & 136 & 50 & 98 \\
\hline May & 9153 & 240 & 2985 & 125 & 33 & 52 \\
\hline June & 9703 & 236 & 2949 & 124 & 30 & 52 \\
\hline July & 15864 & 506 & 1837 & 112 & 12 & 22 \\
\hline August & 21198 & 1011 & 2062 & 89 & 10 & 9 \\
\hline September & 15384 & 417 & 2194 & 44 & 14 & 11 \\
\hline October & 10825 & 262 & 2467 & 62 & 23 & 23 \\
\hline November & 5292 & 143 & 2737 & 76 & 52 & 53 \\
\hline December & 3991 & 141 & 2676 & 127 & 67 & 90 \\
\hline $\begin{array}{l}\text { Monthly } \\
\text { yearly } \\
\text { average }\end{array}$ & $\mathbf{9 0 9 5}$ & $\mathbf{2 8 8}$ & $\mathbf{2 6 0 5}$ & $\mathbf{1 0 4}$ & $\mathbf{2 9}$ & $\mathbf{3 6}$ \\
\hline
\end{tabular}

In the last four years, every 100 new marriages celebrated nationwide in November, another 29 have been unfolded, the average for Bacau being higher, respectively 36 . March is the most harmful in this regard, in Bacau County being over 1.3 times more divorces than marriages.

If we analyze the structure of divorces by duration of marriage, there is noticed a decrease in the share of divorces to marriages of up to four years, maintaining or even decreasing the share of those with a duration of 5-14 years, a slight increase of 1519years and a major growth in the ones that lasted 20 years and over. 


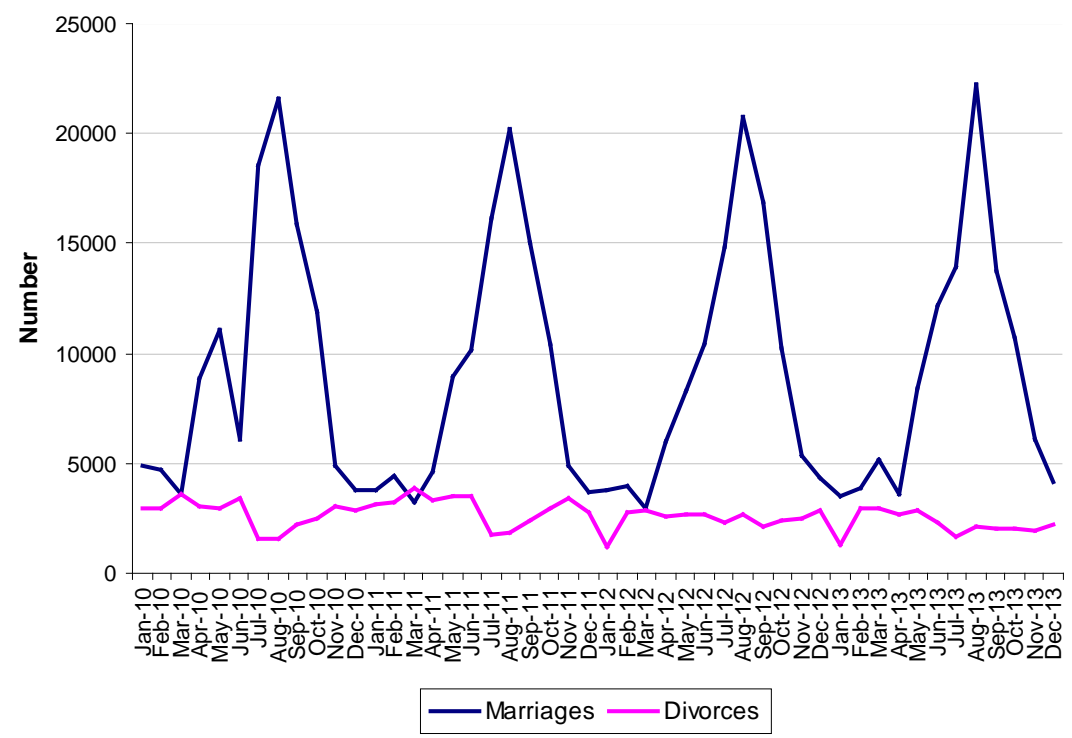

Figure 1 Evolution of the number of marriages and divorces in Romania by month during 2010-2013

Source: I.N.S., Tempo online

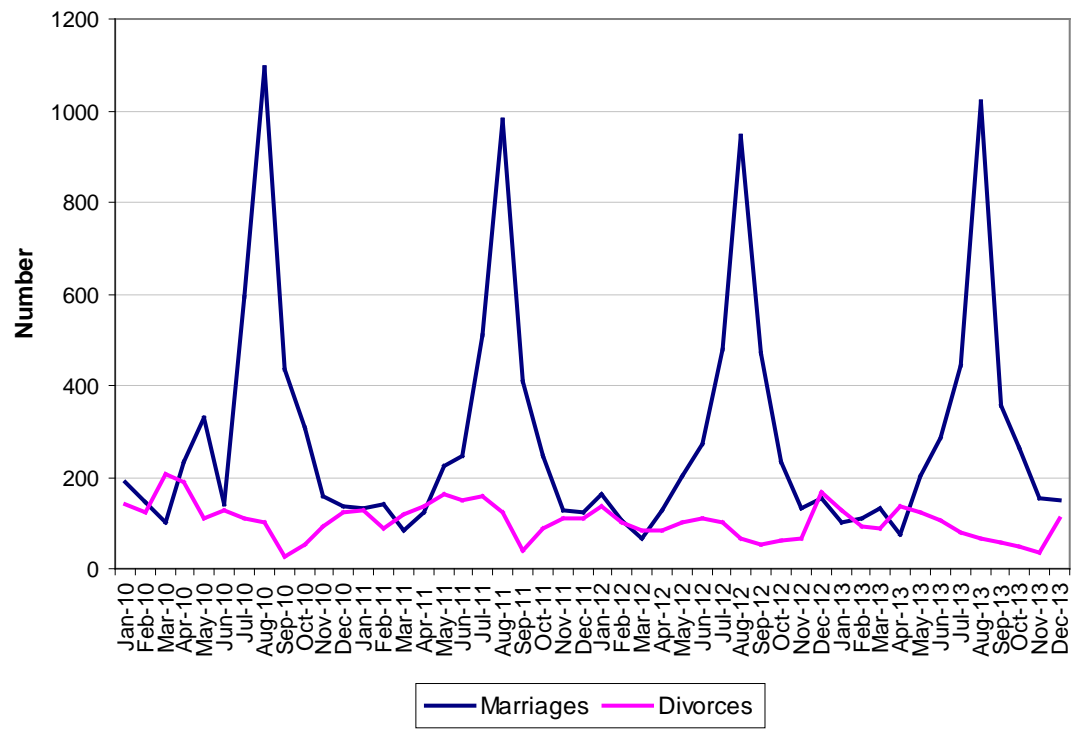

Figure 2 Evolution of the number of marriages and divorces in Bacau county by month during 2010-2013

Source: I.N.S., Tempo online

Thus, in 2012, the structure of divorces by the duration of marriages was the following: 2,4\% after one year, 6,1\% after two years, 6,7\% after 3 years and the same after 4 years, $24,8 \%$ after $5-9$ years, $16,1 \%$ after $10-14$ years, $12 \%$ after $15-19$ years and $20,9 \%$ after 20 years and over. 
Regarding the structure of divorces by the number of remaining minor children after divorce, the share of divorced couples without children increased and the share of all other groups decreased during the last 24 years. At the end of the period, 55,3\% of divorced couples nationwide had no minor child, 31,6\% had one child, $11,1 \%$ had 2 children, 1,4\% had 3 children, $0,4 \%$ had 4 children and $0,2 \%$ of the total had 5 children and over. The same issues are found in the county of Bacau.

In graphs 1 and 2 can be observed the monthly evolution of the number of marriages and divorces in the past four years, compared to the national level and Bacau. Fluctuations by months are similar especially for the marriages where the seasonal factor is clear.

\section{Calculation of the seasonality indices}

As shown in the two graphs shown above, especially in the case of the monthly evolution of marriages, it emerges a cyclical component. This makes the number of marriages to be higher in summer and lower in the winter. On the one hand couples prefers formalizing their marriage and celebrating it in warmer months, but on the other hand, the religious factor puts also a mark. It is known that during all the days of fasting and religious holidays Priests don't officiate marriages. Marriages during these periods of prohibition are only civil marriage, not religious. As most young people prefer to have the civil marriage at the same time with the religious one, the large flow of marriages is visible soon after the major periods of fasting. Because of this reason, immediately after Easter feast, generally starting with May, the number of marriages is exploding. During June there are three weeks of St. Peter and Paul feast, then again it is free for religious celebration of marriage until early August, when another two weeks of feast. In addition, August is the peak month of holidays, which increases the number of marriages, especially if we take into account the young people left to work abroad, not few, who prefer to return to the country in the month of leave and to celebrate their marriage.

The second part of November and most of December comes again with a long period of feast, which correlated with the cold season, lead to a massive decline in the number of marriages.

Following their monthly evolution, it can be observed easily the seasonality of this phenomenon, the chart having every year almost the same trend.

For this reason, I have calculated forward the seasonality indices through the mobile average method. There were calculated mobile averages of 12 terms, as seasonal factor always occurs after 12 months and then were calculated mobile averages centered of two mobile averages each. The weighted average was further applied and seasonality indices were obtained, whose evolution can be seen from the graphs number 4 and 5 Romania versus Bacau County, both for marriages and divorces.

If in among the country six months a year, from May to October, the number of marriages is over the annual monthly average in only three months Bacau manifest this phenomenon (July-September), but in the middle month the gap is well above the national average. Peak month when marriages are formalized remains in August, a month in which the phenomenon of seasonal factor deviates more than 2,3 times the national monthly average and more than 3,5 times in the county of Bacau. 


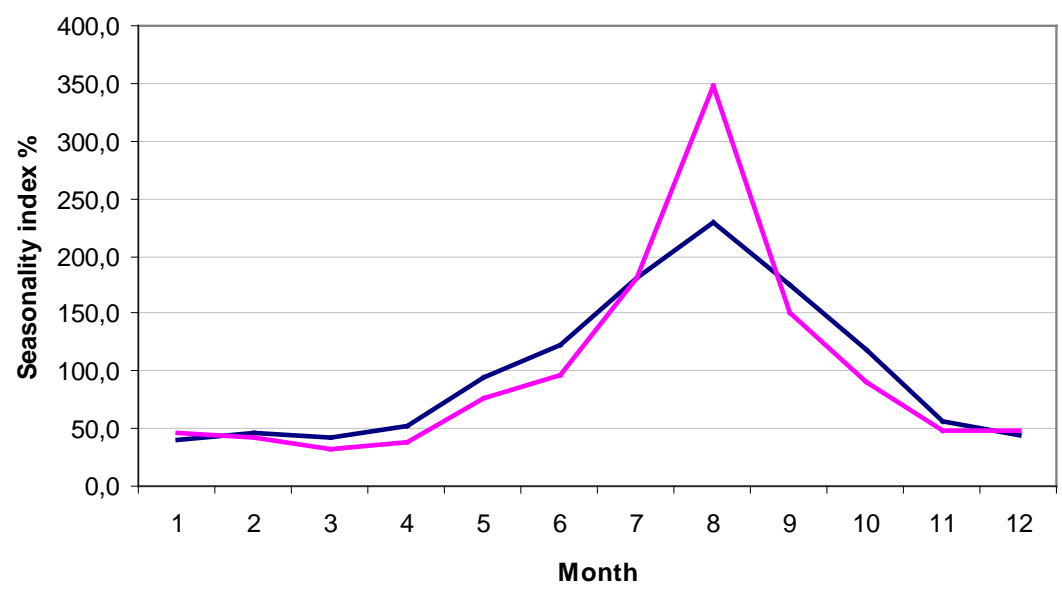

Romania —-Bacău county

Figure 3 Monthly indices of seasonality calculated through the method of mobile averages for marriages during 2010-2013

Source: own calculations based on data from I.N.S.

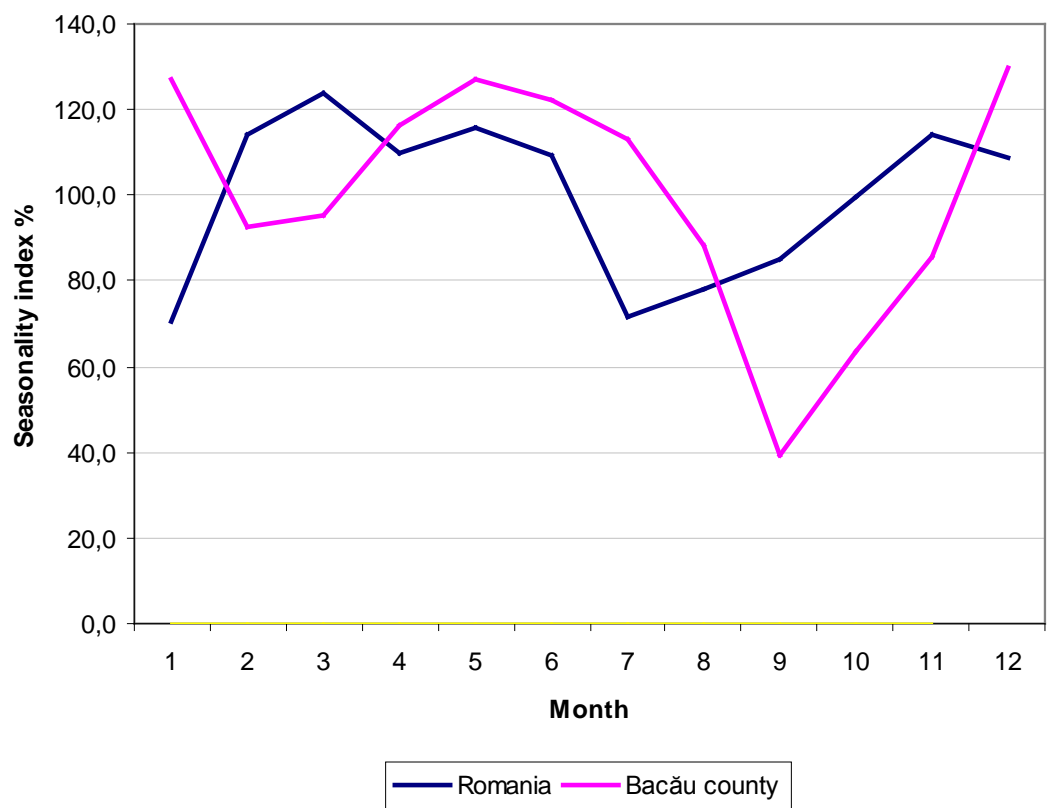

Figure 4 Monthly indices of seasonality calculated through the method of mobile averages for divorces during 2010-2013

Source: own calculations based on data from I.N.S.

Seasonality indices make the number of marriages in July to be $74,4 \%$ higher than the monthly average annually on a national level and $75,4 \%$ in the county of Bacau, and for September to be $+69,1 \%$ at national level and $+44,5 \%$ in Bacau county. 
In the case of divorces, the seasonal factor is found in a lesser extent, given that the official date of divorce is given on the final sentence, which may take several years from the time of bringing the action. We could consider that in a lesser extent, the seasonal factor may be influenced during the summer holidays when fewer legal actions are generally prosecuted in court, otherwise, they being found throughout the year.

\section{Conclusions}

After the 90's, marriages generally tended to decrease, both because of the reduction in population due to migration, and the change in the behavior of couples. More preferred to reserve more time for career and stable living, then to found legally a family and to think about future children. The woman has become more independent, wanting to achieve professional and financial status, to not depend on a man, which is why the average age at first marriage increased over time, leading inevitably to the increase in the average age of mothers at first childbirth.

Couples wish to bring stability to the lives of future children, which is why, with all the freedom after the 90's, as well as due to the tradition, culture and education and the religious factor, the vast majority wanted to formalize their relationship and to widen their family in a legal framework.

In the case of marriages, it is clearly observed, for years, an influence of both seasonal and religious norms that make their number to be much higher in the summer months after the completion of the periods of fasting. Not the same can be said in the case of divorces, the seasonal factor is found in a smaller extent and can be linked only with the smaller number during the summer months, and months when courts generally have vacation.

Monthly seasonality evolution of marriages will surely manifest many years from now because of the factors underlying the choice of the date of their celebration.

\section{References}

Barthelemy, P., Granier, B., Robert, M. (2009), Demografie şi societate, Institutul European.

Harja, E. (2009), Statistică şi econometrie, Bacău, Ed. AlmaMater.

Institutul National de Statistica (2014), TEMPO Online, available at http://www.insse.ro/.

Rotariu, T. (2003), Demografie şi sociologia populaţiei, Ed.Polirom, Iaşi. 